\title{
La constitucionalización del ordenamiento jurídico peruano a la luz de la teoría de Ricardo Guastini
}

The constitutionalization of Peruvian law in the light of the theory of Ricardo Guastini

Luis Robles Trejo ${ }^{1}$, Félix Julca Guerrero ${ }^{1}$, Elmer Robles Blácido ${ }^{1}$ y

Víctor Flores LeIva ${ }^{1}$

\section{RESUMEN}

La finalidad del presente artículo es demostrar el impacto o influencia del paradigma neoconstitucionalista en la reconfiguración del ordenamiento jurídico peruano teniendo como base la teoría jurídica o postulados de Ricardo Guastini. El estudio muestra algunas categorías que permiten comprender de forma adecuada el proceso de constitucionalización del derecho en el ordenamiento jurídico y cómo se puede llegar a que ese proceso se desarrolle de forma óptima. Asimismo, se evalúa el cumplimiento de los postulados de la constitucionalización del derecho propuesto por Ricardo Guastini a fin de determinar si en el Perú se cumple con esas exigencias constitucionales.

Palabras clave: constitución; constitucionalismo; constitucionalización; ordenamiento jurídico; neoconstitucionalismo.

\begin{abstract}
The purpose of this article is to demonstrate the impact or influence of neoconstitutionalist reconfiguration paradigm in Peruvian law on the basis of legal theory or Guastini Ricardo postulates; in this regard it shows some categories for understanding properly the constitutional process of law in the legal system and how you can get to that process develops optimally; and finally compliance with the principles of the constitutionalization proposed by Ricardo Guastini to determine our compliance with these constitutional requirements right is evaluated.
\end{abstract}

Keywords: constitution; constitutionalism; constitutionalization; law; neoconstitutionalism.

\section{ICHIKLLACHAW}

Kay yachay willakuychaw munaa imanaw kay paradigma neoconstitucionalista ratatsin mushuq Piruupa juriidiku pushaqninkuna, tsayta rikaatsikuyta nuna Ricardo Guastini

1 Universidad Nacional «Santiago Antúnez de Mayolo». Huaraz, Perú. 
rurashqanta rikaraykar. Kaychaw kaayishun alli imanaw kunstitusiyunta rurakanqanta niykur kaywan alli justicia rurayta. Tsaynawllam hina chanintsaatsintsik Ricardo Guastini nishqanta tsaynawpan rikaashi maa tsaykuna Piruu markantsikchaw allikush patsaykan.

Pushaq shimikuna: Kunstitusiyun kaq; Kunstitusiyun washay; imanaw kunstitusiyun rurakaq kaq; alli pushaqkuna kaqkuna; mushup kunstitusiyun kaq.

\section{INTRODUCCIÓN}

Con posterioridad a la Segunda Guerra Mundial, se ha construido una nueva forma de entender el derecho que parte de la importancia y necesidad de la protección de los derechos fundamentales y la dignidad humana. Este «nuevo constitucionalismo» reta los fundamentos clásicos de cómo se entendía el derecho centrándose en la materialización del derecho por medio de los principios constitucionales, la garantía jurisdiccional de la Constitución, la relación del derecho con la moral y la importancia de la argumentación.

La constitucionalización del ordenamiento jurídico se da como resultado de un largo proceso de transformación del Estado Legal de Derecho al Estado Constitucional de Derecho (Zagrebelsky, 1995). En la actualidad es inconcebible comprender el ordenamiento jurídico a espaldas de la Constitución, dado que esta es la principal fuente del derecho y condiciona la validez del ordenamiento jurídico. En el Estado Constitucional de Derecho, a diferencia del Estado Legal de Derecho, la Constitución es norma jurídica suprema, tanto como lex legis (jerarquía formal), así como norma normarum (jerarquía material), en razón a que fundamenta la validez de la creación y aplicación de las normas jurídicas integrantes del ordenamiento jurídico.

En este marco, el presente estudio analiza la constitucionalización del ordenamiento jurídico peruano a la luz de la teoría de Ricardo Guastini desde una perspectiva teórica y cualitativa utilizando los métodos histórico, dogmático y exegético, principalmente. La sección de resultados desarrolla dos importantes puntos. El Estado de la cuestión del proceso de constitucionalización del ordenamiento jurídico y sobre la constitucionalización de los ordenamientos jurídicos. La constitucionalización del ordenamiento jurídico se entiende, primero como la introducción de una Constitución formal al ordenamiento jurídico que antes no la tenía. Es pertinente señalar que este sentido no es el idóneo para nuestro propósito de estudio, en la medida que afirma que únicamente existe proceso de constitucionalización en los ordenamientos jurídicos que tienen una Constitución formal, olvidándose que el proceso de constitucionalización del ordenamiento jurídico también se puede dar en base a una Constitución material. Segundo, tiene que ver con el resultado del efecto irradiador que tiene la Constitución del Estado Constitucional en el ordenamiento jurídico, postura adoptada en este estudio. Finalmente, el ordenamiento jurídico producto de su constitucionalización resulta impregnado por normas constitucionales (expresas e implícitas). En ese sentido, un ordenamiento jurídico constitucionalizado se caracterizará por tener un texto constitucional que vincula a todo poder público y privado. Esta Constitución es capaz de condicionar 
la validez de toda acción pública y privada (que atente contra los principios del Estado Constitucional de Derecho), tales como: legislación, jurisprudencia, doctrina, actividad de los actores políticos y privados, entre otros.

\section{MATERIALES Y MÉTODOS}

La investigación fue de tipo jurídico, dogmático y teórico, y por su nivel fue de carácter explicativo. Se aplicó el diseño no experimental, debido a que careció de manipulación la variable independiente, además no contó con grupo de control, su finalidad fue analizar el hecho jurídico tal como se encuentra en la realidad.

Los métodos utilizados fueron: histórico, para analizar los antecedentes y desarrollo histórico del fenómeno jurídico como de las teorías jurídicas. Analítico-sintético para poder descomponer el problema en sus partes y determinar sus características; así como, a partir de dichos elementos entender la configuración o el proceso de constitucionalización. Exegético para el análisis sistemático de la normatividad y para explicar si el ordenamiento jurídico peruano responde a los fundamentos del neoconstitucionalismo. Dogmático para poder estudiar la teoría jurídica del neoconstitucionalismo y los postulados teóricos de Ricardo Guastini. Hermenéutico, para interpretar los textos dentro de un sistema de pensamiento para encontrar su verdadero significado, a partir de los principios y conceptos generales.

Las técnicas utilizadas para la recolección de información fueron: Técnica documental o fichaje, empleándose como instrumentos las fichas textuales, resumen, comentario y bibliográficas. Respecto a la técnica de análisis de la información se empleó la de análisis cualitativo para el análisis doctrinario y teórico de las diversas fuentes de información, y la argumentación jurídica para justificar el proceso de constitucionalización del ordenamiento jurídico a partir del paradigma neoconstitucionalista.

\section{RESULTADOS}

1. Estado de cuestión del proceso de constitucionalización del ordenamiento jurídico

El tratamiento del proceso de constitucionalización del derecho es un asunto complejo cuando no existe un acuerdo sobre nociones generales relacionadas con él. La existencia de un diálogo fructífero y dialéctico no es sino consecuencia de un acuerdo mínimo sobre ciertos postulados relacionados con el proceso de constitucionalización. Por ejemplo, la uniformidad de criterios sobre las nociones conceptuales de derecho, Constitución, derechos fundamentales y principios será fundamental. En la doctrina pueden encontrarse nociones disímiles las unas de las otras. Una de las causas de esta situación es que una noción acerca de la constitucionalización del derecho presupone múltiples nociones, que difícilmente suscitan amplio acuerdo entre sí; por ejemplo, presupone las nociones de Constitución, Estado, derecho, función judicial y derechos fundamentales.

Así, el proceso de constitucionalización del derecho puede partir de diversos puntos de análisis. Como objeto de estudio puede recibir aportes importantes de la historia, 
la teoría jurídica, la sociología, la filosofía política y la economía. Tales disciplinas, desde sus perfiles, hacen un aporte importante que nutre la comprensión adecuada del fenómeno. En consecuencia, la falta de consenso más o menos claro da lugar a posiciones a favor y en contra del proceso de constitucionalización del derecho. Desde la economía, se ha recibido grandes críticas a este proceso, en especial con el argumento de los aspectos ineficientes a que lleva el derecho constitucionalizado. La sociología, por su parte, ha entendido el proceso como ineficaz, pues el gran catálogo de promesas difícilmente puede ser cumplido. La filosofía moral ha visto el proceso como un lugar propicio para la institucionalización de sus debates. Desde las concepciones clásicas del derecho privado, se entiende que se afrentan sus presupuestos básicos.

En suma, la constitucionalización del derecho se ha constituido como uno de los temas más importantes en las últimas décadas en el ordenamiento jurídico peruano, y en especial en los ordenamientos jurídicos que han bebido de los proyectos constitucionales europeos de la Segunda Posguerra. Las características y la función en el ordenamiento jurídico de esta forma de entender el constitucionalismo ha dado pie a interesantes desarrollos doctrinales y a intrincados debates, tal es así que la Revista Doxa Nº 34 (2012) dedica toda la edición a discutir este tema.

\section{Sobre la constitucionalización de los ordenamientos jurídicos}

Hace más de una década se viene utilizando el término constitucionalización para nombrar al fenómeno que ha introducido cambios radicales en los ordenamientos jurídicos de algunos países de Europa continental, principalmente España, Francia, Alemania e Italia (Bernal, 2009: 19). El origen de estos cambios ha sido la propia Constitución, convertida en una norma auténticamente obligatoria cuya fuerza es irradiada a todo el ordenamiento jurídico (Carbonell, 2003: 286).

Por su parte, Ricardo Guastini define a la constitucionalización como el «proceso de transformación de un ordenamiento, al término del cual, el ordenamiento en cuestión resulta totalmente 'impregnado' de las normas constitucionales» (2001: 153). Esto supone que la constitucionalización comienza en la Constitución, pero termina extendiéndose a toda la estructura normativa. Y es que un ordenamiento constitucionalizado se caracteriza por tener una Constitución extremadamente invasiva y desbordante, en cuanto regula los aspectos más importantes de la vida política y social, incluyendo el comportamiento de los actores políticos y las relaciones entre particulares (Ibíd.). Pero también condiciona la validez de la legislación, el desarrollo de la jurisprudencia y el estilo doctrinal. De modo que un ordenamiento constitucionalizado tiene una Constitución con plena fuerza obligatoria, generadora de efectos jurídicos inmediatos y que funciona como parámetro de validez para la interpretación de todas las normas jurídicas.

En este contexto, Guastini (2001: 154-164) ha identificado siete condiciones que un determinado ordenamiento debe satisfacer para poder considerarlo constitucionalizado, si bien aclara que la constitucionalización no es una propiedad «todo o nada», en el sentido de que el ordenamiento esté o no constitucionalizado en términos absolutos. 
Tal como lo expresa el mismo Guastini se «trata más bien de una cuestión de grado debido a que un sistema puede estar constitucionalizado en mayor o menor medida, dependiendo de cuántas y cuáles condiciones estén satisfechas en el seno de dicho sistema» (Guastini, 2010: 153).

Siguiendo al propio Guastini, estas siete condiciones que son necesarias para poder decir que un determinado ordenamiento jurídico está «constitucionalizado», son:

a. La existencia de una Constitución rígida. El propio Guastini apunta sobre este rasgo que la constitucionalización será más acentuada en aquellos ordenamientos en los que existan principios (tanto expresamente formulados como implícitos) que no puedan ser modificados en modo alguno: ni siquiera mediante el procedimiento de revisión constitucional (2001: 155). En otras palabras, a una Constitución más rígida corresponde un mayor efecto de «constitucionalización» de todo el ordenamiento. Esto es, una Constitución escrita que tiene protección frente a la legislación secundaria en tanto que no puede ser derogada, modificada o abrogada a través del procedimiento legislativo ordinario, sino mediante uno de tipo especial, más complejo.

b. La garantía jurisdiccional de la Constitución. Dicha garantía permite hacer de la rigidez algo más que un simple postulado de buenas intenciones. La rigidez, para ser tal, debe poder imponerse frente a las leyes y al resto del ordenamiento jurídico. Los modelos para llevar a cabo el control de constitucionalidad son muy variados y pueden analizarse a la vista de su mayor o menor efectividad. Guastini distingue el modelo americano del modelo francés y del modelo continental europeo (Italia, España, Alemania, etcétera) (2001: 155-157); en consecuencia, se refiere al control constitucional de las leyes, el cual puede adoptar distintas modalidades (a posteriori/a priori, in concreto/ in abstracto, etcétera), pero siempre ejercido por un órgano judicial.

c. La fuerza vinculante de la Constitución. Este punto se concreta a través de la idea de que las normas constitucionales (todas, con independencia de su estructura y de su contenido) son plenamente aplicables y obligan a sus destinatarios. Tradicionalmente, no se consideraban como son vinculantes las normas programáticas (entre ellas la doctrina tradicional solía ubicar las relativas a los derechos sociales) o los principios (2001: 157-158); en consecuencia significa que todas sus normas son obligatorias y capaces de producir efectos jurídicos inmediatos.

d. La «sobreinterpretación» de la Constitución. Dicha sobre-interpretación se produce cuando los intérpretes constitucionales (que son tanto los encargados de desempeñar la jurisdicción constitucional como los jueces ordinarios, los demás órganos del Estado y los juristas en general) no se limitan a llevar a cabo una interpretación literal de la Constitución, sino que adoptan una interpretación extensiva, utilizando cuando sea posible el argumento a simili. A través de este tipo de interpretación, se pueden extraer del texto constitucional innumerables normas implícitas, idóneas para regular casi cualquier aspecto de la vida social y política y, por ende, idóneas también para condicionar de forma muy incisiva el contenido de una parte del ordenamiento jurídico. «Cuando la Constitución es sobre-interpretada (apunta Guastini) no quedan espacios vacíos de 
-o sea, «libres» del- derecho constitucional: toda decisión legislativa está prerregulada (quizás aún, minuciosamente regulada) por una u otra norma constitucional. No existe ley que pueda escapar al control de legitimidad constitucional» (2001: 58-160); lo que significa la necesidad de que el texto constitucional sea interpretado extensivamente para obtener de él las innumerables normas implícitas, reguladoras de cualquier aspecto de la vida social y política.

e. La aplicación directa de las normas constitucionales. Esta quinta condición para la constitucionalización del ordenamiento jurídico tiene que ver con dos cuestiones: a) el entendimiento de que la Constitución rige también las relaciones entre particulares y no es un texto dirigido solamente a las autoridades u órganos públicos; y b) que todos los jueces pueden aplicar la Constitución, incluso sus normas programáticas o normas de principio. Estos dos aspectos no se encontraban en el constitucionalismo clásico, pero se han ido conquistando de forma paulatina en los años recientes tanto por la doctrina como por la jurisprudencia constitucionales (2001: 160-161), lo que significa que la Constitución debe ser aplicada directamente por todas las autoridades normativas y en ocasión de cualquier controversia, incluso las de carácter privado.

f. La interpretación conforme de las leyes. Guastini apunta que esta condición no tiene que ver con la interpretación de la Constitución, sino con la interpretación de la Ley (2007: 161-162). La interpretación conforme se da cuando, al tener la posibilidad un juez de aplicar a un caso concreto la interpretación X1 de una ley o la interpretación $\mathrm{X} 2$, opta por la que sea más favorable para cumplir de mejor forma (de manera más completa) con algún mandato constitucional. Desde luego, la interpretación conforme también significa que, ante una interpretación de la ley que vulnera el texto constitucional u otra interpretación de la misma ley que no lo vulnera, el juez prefiere esta última; en consecuencia esta condición se refiere al deber del juez de interpretar la ley de acuerdo con el texto de la Constitución, buscando armonizar la primera con la segunda y evitar así un conflicto entre ambas.

g. La influencia de la Constitución sobre las relaciones políticas. La última de las condiciones de constitucionalización del ordenamiento a las que se refiere Guastini consiste en una pluralidad de elementos entre los que se puede mencionar los siguientes: a) que la Constitución prevea un sistema de solución de diferencias políticas entre órganos del Estado (incluso entre órganos de los diversos niveles de gobierno en los Estados que sean federales o regionales), que permita a un órgano jurisdiccional resolverlos aplicando normas constitucionales; b) que los órganos jurisdiccionales encargados de la justicia constitucional no asuman actitudes de self restraint (autocontrol) frente a lo que en alguna época se ha llamado las «political questions» (cuestiones políticas), sino que todos los espacios del quehacer público del Estado sean reconducibles a parámetros de enjuiciamiento constitucional; y c) que las normas constitucionales sean utilizadas por los principales actores políticos para argumentar y defender sus opciones políticas o de gobierno (2001: 163-164); por lo que dicha condición se traduce en el hecho de que esta norma confiere a un tribunal constitucional la facultad de resolver los conflictos competenciales de los poderes públicos, entendidos como desacuerdos políticos en 
torno a las relaciones de poder entre los órganos del Estado; así como en el control que ejerce el propio tribunal sobre la discrecionalidad política del legislador, a través de distintos mecanismos (Guastini, 2010: 153).

\section{DISCUSIÓN}

1. Sobre las condiciones de la constitucionalización del ordenamiento jurídico peruano Guastini (2001: 154) sostiene que las dos primeras son condiciones necesarias de la constitucionalización en virtud de que ella sería inconcebible en su ausencia. Pero ha omitido fijar un orden jerarquizado entre las demás, lo que impide conocer la importancia concreta de cada una. Simplemente ha formulado algunas conjeturas que no permiten determinar con exactitud cuáles son las que tienen mayor valor o peso. Por ejemplo, Guastini cree que las condiciones tres a siete son suficientes de un grado distinto de constitucionalización; la tercera y la quinta son elementos esenciales de este proceso; la cuarta y la sexta son condiciones meramente importantes; la tercera y la cuarta mantienen un nexo muy estrecho entre sí; la quinta se encuentra vinculada tanto a la tercera como a la cuarta, y así por el estilo. En un trabajo más reciente, Guastini (2010: 157) ha reiterado que las dos primeras son condiciones necesarias para que un ordenamiento cualquiera esté constitucionalizado. Las demás son aspectos o indicios del proceso de constitucionalización. Ello significa que no es posible saber cuánto vale cada una con el fin de precisar qué tan constitucionalizado está un determinado ordenamiento. Consecuentemente, todo aquel que no cumpla las condiciones tres, cuatro, cinco, seis o siete, o las cumpla solo de manera aproximada, será un ordenamiento constitucionalizado en términos parciales. Es importante no perder de vista esta última acotación porque el derecho peruano se encuentra precisamente en este supuesto: el de la constitucionalización parcial. Dando por descontadas las dos primeras condiciones que son sine qua non, diríase que el orden jurídico peruano está parcialmente constitucionalizado puesto que en él es posible reconocer la presencia de (por lo menos) algunas de las demás condiciones de ese proceso.

2. Sobre la fenomenología de la constitucionalización en el Perú o proceso de constitucionalización del ordenamiento jurídico peruano

2.1 La existencia de una Constitución rígida. La Constitución peruana de 1993 cumple con los dos presupuestos planteados por Guastini para tener una constitución rígida; el primero, la positivización de los derechos o reconocimiento expreso de los derechos y libertades, tal como lo hace en el artículo $2^{\circ}$ y el reconocimiento de los derechos implícitos a través del artículo $3^{\circ}$ y segundo, el reconocimiento o positivización del procedimiento agravado para modificar el contenido de la constitución; es decir la regulación constitucional de la reforma constitucional prevista en el artículo $206^{\circ}$ de la constitución, estableciéndose el órgano competente, y procedimiento a seguir para una reforma constitucional. 
2.2 La garantía jurisdiccional de la Constitución. La Constitución de 1993 ha incorporado como parte de su contenido las condiciones planteadas por Guastini como son: primero, el reconocimiento del principio de supremacía constitucional en los artículos $51^{\circ}$ y $138^{\circ}$; segundo, el reconocimiento de dos modelos para llevar a cabo el control de constitucionalidad como son el control difuso regulado en el artículo $138^{\circ}$ y control abstracto regulado en el artículo $201^{\circ}$ de la constitución.

2.3 La fuerza vinculante de la Constitución. La Constitución, dentro de un modelo neoconstitucionalista, deja de concebirse como mera realidad retórica para pasar a formularse como una realidad normativa y, por tanto, efectivamente vinculante a sus destinatarios: el poder político (artículo $45^{\circ}$ ) y los particulares (artículo 38 ). Esta norma jurídica es la base (o cúspide, según se quiera ver) del entero ordenamiento jurídico del Estado, de modo que se convierte en la norma suprema, situada por encima del resto de normas (artículo $51^{\circ}$ ).

Esta norma jurídica fundamental tiene un contenido caracterizado por un elemento formal y otro material. El elemento formal consiste en que las disposiciones constitucionales -en particular las disposiciones fundamentales- se formulan a través de un lenguaje general que las hacen abiertas, indeterminadas y necesitadas de concreción. El elemento material, por su parte, consiste en que las disposiciones constitucionales -en particular, las disposiciones fundamentales- tienen un importante contenido axiológico, a través del cual formula los valores básicos de una sociedad que han de ser asumidos y seguidos como fin, tanto por el poder político como por los particulares, llegando incluso a justificar del poder político verdaderas obligaciones de acción. Esto permite hablar de orden jurídico materializado (Acosta, 1998).

2.4 La «sobreinterpretación» de la Constitución. La influencia del derecho constitucional se extiende, desde esta perspectiva, tanto a su objeto tradicional de regulación, que son los poderes públicos, sus competencias y sus relaciones con los particulares, como a las diversas ramas del derecho privado, que también se ven condicionadas por los mandatos constitucionales, entre los cuales destacan - por la magnitud de su impacto sobre el derecho privado- las normas constitucionales que establecen los derechos fundamentales; como apunta Konrad Hesse: «Los derechos fundamentales influyen en todo el Derecho... no sólo cuando tiene por objeto las relaciones jurídicas de los ciudadanos con los poderes públicos, sino también cuando regula las relaciones jurídicas entre los particulares. En tal medida sirven de pauta tanto para el legislador como para las demás instancias que aplican el Derecho, todas las cuales al establecer, interpretar y poner en práctica normas jurídicas habrán de tener en cuenta el efecto de los derechos fundamentales» (Hesse, 1996: 93).

Además, ocurre que por medio de la sobreinterpretación, el intérprete constitucional extrae los contenidos normativos implícitos en el texto, creando normas jurídicas no expresadas. Y esta tarea de hacer explícito lo que no lo es se desarrolla mediante la técnica señalada de extender el significado de la disposición constitucional para cubrir casos no previstos por los autores de la misma, lo que supone equiparar a la sobreinterpretación de la Constitución con la interpretación extensiva, en tanto pertenece al 
género de la llamada interpretación correctora, entendida como la que atribuye a un texto, no su significado literal más inmediato, sino uno diverso, el cual puede ser más restringido o más extenso. Y solo si el significado asignado es más amplio que el estrictamente literal se hablará de interpretación extensiva.

En ese sentido, el Tribunal Constitucional peruano en reiteradas jurisprudencias ha precisado que, reconocida la naturaleza jurídica de la Constitución del Estado, debe reconocerse también la posibilidad de que sea objeto de interpretación. No obstante, la particular estructura normativa de sus disposiciones que, a diferencia de la gran mayoría de las leyes, no responden en su aplicación a la lógica subsuntiva (supuesto normativo -subsunción del hecho- consecuencia), exige que los métodos de interpretación constitucional no se agoten en aquellos criterios clásicos de interpretación normativa (literal, teleológico, sistemático e histórico), sino que abarquen, entre otros elementos, una serie de principios que informan la labor hermenéutica del juez constitucional (STC Exp. N 5854-2005-PA/TC, F.J. 12).

Tales principios son: El principio de unidad de la Constitución, el principio de concordancia práctica; el principio de corrección funcional; el principio de función integradora; el principio de fuerza normativa de la Constitución (Hesse, 1992: 45-47).

a) El principio de unidad de la Constitución, conforme al cual la interpretación de la Constitución debe estar orientada a considerarla como un «todo» armónico y sistemático, a partir del cual se organiza el sistema jurídico en su conjunto.

b) El principio de concordancia práctica, en virtud del cual toda aparente tensión entre las propias disposiciones constitucionales debe ser resuelta «optimizando» su interpretación, es decir, sin «sacrificar» ninguno de los valores, derechos o principios concernidos, y teniendo presente que, en última instancia, todo precepto constitucional, incluso aquellos pertenecientes a la denominada «Constitución orgánica» se encuentran reconducidos a la protección de los derechos fundamentales, como manifestaciones del principio-derecho de dignidad humana, cuya defensa y respeto es el fin supremo de la sociedad y el Estado (artículo $1^{\circ}$ de la Constitución).

c) El principio de corrección funcional. Este principio exige al juez constitucional que, al realizar su labor de interpretación, no desvirtúe las funciones y competencias que el Constituyente ha asignado a cada uno de los órganos constitucionales, de modo tal que el equilibrio inherente al Estado Constitucional, como presupuesto del respeto de los derechos fundamentales, se encuentre plenamente garantizado.

d) El principio de función integradora: El «producto» de la interpretación solo podrá ser considerado como válido en la medida que contribuya a integrar, pacificar y ordenar las relaciones de los poderes públicos entre sí y las de éstos con la sociedad.

e) El principio de fuerza normativa de la Constitución: La interpretación constitucional debe encontrarse orientada a relevar y respetar la naturaleza de la Constitución como norma jurídica, vinculante in toto y no solo parcialmente. Esta vinculación alcanza a todo poder público y a la sociedad en su conjunto. 
2.5 La aplicación directa de las normas constitucionales. La concepción de la Constitución como norma jurídica vinculante trae consigo el carácter, también vinculante (STC EXP. N 4853-2004-PA/TC, F.J.28); en ese sentido la Constitución de 1993 ha materializado las condiciones planteadas por Guastini en los artículos $38^{\circ}$ y $45^{\circ}$ de esta forma tal como lo señala Eduardo García De Enterría, la constitución goza de una particularidad de ser considerada como norma jurídica (1991: 197-205).

En ese sentido, también nuestro Tribunal Constitucional en reiteradas jurisprudencias ha reconocido que el tránsito del Estado Legal de Derecho al Estado Constitucional de Derecho supuso, entre otras cosas, abandonar la tesis según la cual la Constitución no era más que una mera norma política, esto es, una norma carente de contenido jurídico vinculante y compuesta únicamente por una serie de disposiciones orientadoras de la labor de los poderes públicos, para consolidar la doctrina conforme a la cual la Constitución es también una Norma Jurídica, es decir, una norma con contenido, dispositivo capaz de vincular a todo poder (público o privado) y a la sociedad en su conjunto.

Es decir, significó superar la concepción de una pretendida soberanía parlamentaria, que consideraba a la ley como la máxima norma jurídica del ordenamiento, para dar paso - de la mano del principio político de soberanía popular-al principio jurídico de supremacía constitucional, conforme al cual, una vez expresada la voluntad del Poder Constituyente con la creación de la Constitución del Estado, en el orden formal y sustantivo presidido por ella no existen soberanos, poderes absolutos o autarquías. Todo poder devino entonces en un poder constituido por la Constitución y, por consiguiente, limitado e informado, siempre y en todos los casos, por su contenido jurídico-normativo (STC Exp. N 5854-2005-PA/TC, F.J. 3).

\subsection{La interpretación conforme de las leyes}

Se debe tener en cuenta en esta condición dos supuestos:

a) La supremacía de la Constitución, que tiene como corolario la muerte de la ley, según fue concebida por la ideología del Estado liberal de derecho, con los caracteres de generalidad y abstracción. En el Estado constitucional, en efecto, la ley deja de ser general y abstracta debido a la «pulverización» del derecho legislativo, ocasionada por la multiplicación de leyes sectoriales y temporales. Por lo demás, la ley también pierde su calidad de fuente suprema del ordenamiento jurídico al quedar subordinada a un poder más alto -el de la Constitución. Como resultado, Gustavo Zagrebelsky, uno de los primeros teóricos del Estado constitucional, ha constatado que: «La ley, un tiempo medida exclusiva de todas las cosas en el campo del derecho, cede... el paso a la Constitución y se convierte ella misma en objeto de medición. Es destronada en favor de una instancia más alta» (1995: 40). En el fondo, la llamada crisis de la ley obedece a múltiples factores de cambio sumamente complejos: se puede identificar tanto causas externas como internas al ordenamiento jurídico. Entre estas últimas figura precisamente el impacto de la normativa constitucional sobre la ley que termina relegándola a un segundo plano (De Cabo, 2000: 73). 
b) La rematerialización de la Constitución, que significa que ésta se configura como una norma rematerializada, en el sentido de que posee una serie de contenidos materiales en forma de principios, valores y derechos fundamentales. Dicho rasgo comporta como consecuencia que la Constitución, en cuanto norma axiológicamente suprema, condicione la producción de las leyes, no sólo en el aspecto formal relativo a su producción, sino también material o sustancial, concerniente al contenido de las mismas. De ahí que las leyes puedan ser invalidadas por el tribunal constitucional cuando exhiban un contenido contradictorio con los principios de justicia que la Constitución consagra. En este contexto es donde cobra especial relevancia el control de la Constitución por parte de los órganos judiciales (Prieto, 1999: 15).

En consecuencia, esta condición de la constitucionalización supone que para los jueces y demás operadores del derecho es obligatorio interpretar las leyes de manera tal que su significado esté de acuerdo con el de la Constitución, en cuanto norma suprema del ordenamiento. Guastini la llama interpretación «adecuadora» o «armonizante» de las leyes. En ese sentido, la interpretación adecuadora es aquélla que adecúa, armoniza la ley a la Constitución (se entiende, previamente interpretada), eligiendo - frente a una doble posibilidad interpretativa - el significado (es decir, la norma) que evita toda contradicción entre ley y Constitución. El efecto de semejante interpretación es obviamente el de conservar la validez de una ley que diversamente debería ser declarada inconstitucional (Gascón y García, 2005: 286-287).

2.7 La influencia de la Constitución sobre las relaciones políticas. La Constitución peruana ha constitucionalizado la pluralidad de elementos propuesta por Guastini, así tenemos: a) que la Constitución prevea un sistema de solución de diferencias políticas entre órganos del Estado (incluso entre órganos de los diversos niveles de gobierno: nacional, regionales y locales), que permita a un órgano jurisdiccional resolverlos aplicando normas constitucionales; es el caso del proceso competencial regulado en el artículo 202.3 de la constitución b) Que todos los espacios del quehacer público del Estado sean reconducibles a parámetros de enjuiciamiento constitucional; al reconocerse en los artículos $3^{\circ}$ y $43^{\circ}$ de la Constitución Política del Perú el Estado Social y Democrático de Derecho, se ha incorporado el principio de interdicción o prohibición de todo poder ejercido en forma arbitraria e injusta. Este principio tiene un doble significado: (i) en un sentido clásico y genérico, la arbitrariedad aparece como el reverso de la justicia y el derecho; (ii) en un sentido moderno y concreto, la arbitrariedad aparece como lo carente de fundamentación objetiva, lo incongruente y contradictorio con la realidad que ha de servir de base a toda decisión. Es decir, como aquello desprendido o ajeno a toda razón de explicarlo (STC Exp. No 0090-2004-AA/TC); y c) que las normas constitucionales sean utilizadas por los principales actores políticos para argumentar y defender sus opciones políticas o de gobierno; por lo que dicha condición se traduce en el hecho de que esta norma confiere a un tribunal constitucional la facultad de resolver los conflictos competenciales de los poderes públicos, facultad reconocida en el artículo 202.3 de la Constitución; así como en el control que ejerce el propio tribunal sobre la discrecionalidad política del legislador, a través del proceso de inconstitucionalidad, regulada en el artículo 200.4 y 202.1 de la Constitución. 
3. Crítica a los postulados jurídicos propuestos por Ricardo Guastini para la constitucionalización del ordenamiento jurídico

Al respecto, el profesor Ricardo Guastini (2001) al momento de señalar algunas de las condiciones de constitucionalización del ordenamiento jurídico, sólo hace referencia a condiciones formales de constitucionalización, no menciona a las condiciones materiales. Medir el grado de constitucionalización de un ordenamiento jurídico en base a condiciones formales es desconocer el valor innato de los derechos fundamentales, pues tácitamente se afirma que los derechos fundamentales son creados por el constituyente, y no que éste únicamente se limita a reconocerlos en los textos constitucionales.

En consecuencia, el proceso de constitucionalización del ordenamiento jurídico no se mide -exclusivamente- con condiciones formales de constitucionalización, también es importante satisfacer las condiciones materiales. De lo contrario, estaremos ante un ordenamiento jurídico constitucionalizado en sentido formal que es derrotable por ser insuficiente y no garantista (García, 2011). Lo formal siempre es derrotable por lo material. Lo ideal es el ordenamiento jurídico constitucionalizado en sentido formal y material. Entonces, se dirá que un ordenamiento jurídico está constitucionalizado en la medida que cumpla con ambas condiciones de constitucionalización (Aldunate, 2010).

Es pertinente señalar que el catálogo de las condiciones de constitucionalización que expresamos párrafos arriba es el punto de partida; se podrá agregar algunos más, siempre que haga del proceso de constitucionalización del ordenamiento jurídico el más respetuoso de los derechos fundamentales y de los principios del Estado Constitucional de Derecho. Además, se debe tener en consideración que el concepto de constitucionalización no es una cuestión absoluta, sino de grado. (Aldunate, 2010). Es decir, que a un ordenamiento jurídico se le puede calificar de más o menos constitucionalizado. Todo dependerá de cuántas de las condiciones (formales y materiales) de constitucionalización se han cumplido.

\section{CONCLUSIONES}

El ordenamiento jurídico constitucionalizado se caracteriza, según Ricardo Guastini por tener una Constitución extremadamente invasiva y desbordante, en cuanto regula los aspectos más importantes de la vida política y social, incluyendo el comportamiento de los actores políticos y las relaciones entre particulares. Pero también condiciona la validez de la legislación, el desarrollo de la jurisprudencia y el estilo doctrinal. De modo que un ordenamiento constitucionalizado tiene una Constitución con plena fuerza obligatoria, generadora de efectos jurídicos inmediatos y que funciona como parámetro de validez para la interpretación de todas las normas jurídicas.

La constitucionalización de las distintas áreas del Derecho es un fenómeno cada vez más arraigado en nuestra cultura y contexto jurídicos. Tal vez la forma más evidente en que se haya manifestado sea el creciente protagonismo del Tribunal Constitucional, supremo intérprete de la Constitución, en la significación y resignificación de conceptos, derechos y principios jurídicos que, a través de sus sentencias, han afectado a todas las 
áreas y disciplinas del derecho, lo que se ha denominado como «constitucionalización del ordenamiento jurídico».

En el caso peruano, a la Constitución se le ha reconocido una supremacía jurídica, tanto como lex legis (jerarquía formal) dentro de la jerarquía normativa clásica, así como norma normarum (jerarquía material), en tanto fundamenta la validez de la creación y aplicación del resto de normas, es decir, como principal fuente de Derecho (artículos $51^{\circ}$ y $138^{\circ}$ ). Es de aquí precisamente que deriva la importancia que ha adquirido el Tribunal Constitucional, su jurisprudencia, que en buena cuenta no es más que un ejercicio de control constitucional (Artículos $201^{\circ}$ y $202^{\circ}$ ). Ejercicio que, desde luego, no se limita a una mera verificación de que un hecho se ajuste o no al texto de una norma, sino que se expresa en un proceso de interpretación y argumentación jurisprudencial (Artículos 3, $43^{\circ} 35^{\circ}$ y $200^{\circ}$ ).

El carácter de fuerza normativa de la Constitución tiene su origen en la concepción de la Constitución como norma jurídica vinculante, lo que trae consigo el carácter, también vinculante, es decir dotado de una eficacia real y de una dimensión objetiva que garantiza la protección activa de los derechos fundamentales por parte del Estado. Los principios constitucionales articulan y guían una comunidad jurídica y política; por ello es que requieren ser interpretados en cada caso concreto en donde se suscite un conflicto que los cuestione o confronte (Artículos $38^{\circ}, 45^{\circ}, 200^{\circ}$ y $202^{\circ}$ ).

De las condiciones propuestas por Ricardo Guastini para que un ordenamiento jurídico sea constitucionalizado, en el caso peruano, la Constitución vigente ha incorporado -por lo menos formalmente- tales condiciones; por lo que el ordenamiento jurídico peruano estaría orientándose hacia una constitucionalización -por lo menos parcialen los términos indicados.

Finalmente, Guastini al momento de señalar las condiciones de constitucionalización del ordenamiento jurídico, solo hace referencia a condiciones formales de constitucionalización, no menciona a las condiciones materiales. Medir el grado de constitucionalización de un ordenamiento jurídico en base a condiciones formales es desconocer el valor innato de los derechos fundamentales, pues tácitamente se afirma que los derechos fundamentales son creados por el constituyente, y no que este únicamente se limita a reconocerlos en los textos constitucionales; por lo que concluimos que el ordenamiento jurídico es más o menos constitucionalizado.

\section{REFERENCIAS BIBLIOGRÁFICAS}

Acosta, José. 1998. Formación de la Constitución y jurisdicción constitucional. Madrid: Tecnos.

Aldunate, Eduardo. 2010. «Aproximación conceptual y crítica al neoconstitucionalismo». Revista de Derecho, Vol. XXIII, No 1. Valparaíso. 9-102. <http://dx.doi. org/10.4067/S0718-09502010000100004> [Consulta: 12-10-15].

Bernal, Carlos. 2009. El neoconstitucionalismo y la normatividad en el derecho. Bogotá: Universidad Externado de Colombia.

Carbonell, Miguel (ed.). 2003. Neoconstitucionalismo(s). Madrid: Trotta. 
De Cabo, Carlos. 2000. Sobre el concepto de ley. Madrid: Trotta.

García, Alfonso. 2011. La incidencia de la derrotabilidad de los principios iusfundamentales sobre el concepto de Derecho. <http://www.dirittoequestionipubbliche.org/D_Q-3/ studi/D_Q-3_studi_Figueroa.pdf> [Consulta: 07-08-15].

García, Eduardo. 1991. La Constitución como norma y el Tribunal Constitucional. Madrid: Civitas.

Gascón, Marina y García, Alfonso. 2005. La argumentación en el derecho. 2da. ed. Lima: Palestra.

Guastini, Ricardo. 2001. «La 'constitucionalización’ del ordenamiento jurídico: el caso italiano». En Carbonell, Miguel (ed.). Estudios de teoría constitucional. México: Fontamara. 153-183.

Guastini, Ricardo. 2010. «La ‘constitucionalización’ del ordenamiento: concepto y condiciones». En Interpretación, Estado y Constitución. Lima: Ara Editores. 153-166.

Hesse, Konrad. 1992. Escritos de Derecho Constitucional. 2da. ed. Traducción de Pedro Cruz Villalón. Madrid: Centro de Estudios Constitucionales.

Hesse, Konrad. 1996. «Significado de los derechos fundamentales». En Benda, Maihofer, Vogel, Hesse y Heyde (eds.). Manual de derecho constitucional. Madrid: Marcial Pons.

Prieto, Luis. 1999. Constitucionalismo y positivismo. 2a. ed. México: Fontamara.

Zagrebelsky, Gustavo. 1995. El derecho dúctil. Ley, derechos, justicia. Traducción de Marina Gascón Abellán. Madrid: Trotta.

Fecha de recepción: 14 de noviembre de 2015

Fecha de aceptación: 03 de diciembre de 2015

\section{Correspondencia}

Luis Robles Trejo

llrobles@hotmail.com 